\title{
Influence of Indomethacin on Lens Regeneration in the Newt Notophthalmus viridescens
}

\author{
Thomas G. Connelly \\ Department of Anatomy and Center for Human Growth and Development \\ The University of Michigan, Ann Arbor, Michigan 48109 USA
}

\begin{abstract}
Summary. Following lentectomy newts were injected with indomethacin in a variety of carrier solutions at doses ranging from $1.2-120 \mathrm{mg} / \mathrm{kg}$ body weight every other day for 15-17 days. The results show that injection of this drug according to the regimen used has no significant effect on regeneration of the lens. The data suggest, but do not prove, that prostaglandins may not play a major role in the early phases of lens regeneration in the newt.
\end{abstract}

Key words: Indomethacin - Prostaglandins - Lens - Regeneration Metaplasia.

Removal of the lens from the eye of an adult newt initiates events leading to the metaplastic transformation of iris epithelial cells at the mid-dorsal pupillary margin into lens cells and the regeneration of a new lens (Yamada, 1967). The iris epithelial cells are induced to synthesize increased quantities of ribosomal RNA (Reese et al., 1969; Reese, 1973) and to reenter the cell cycle within the first four days following lentectomy (Yamada et al., 1975). The pigmented cells undergo a process called cytoplasmic shedding during which large amounts of cytoplasm containing melanosomes are lost from the cell (Dumont and Yamada, 1972). Macrophages migrate into the optic chamber and the iris epithelium and engulf the cellular debris (Dumont and Yamada, 1972). Although there is no direct damage to the iris, there is a loss of ocular fluid and damage to the cornea at the time of lens removal. There are several parallels between the early events of lens regeneration, including the mobilization of macrophages, and an inflammatory response. There is no evidence concerning the nature of the stimulus responsible for the initiation of the Wolffian regeneration process. It is known that in the rabbit, trauma to the iris or cornea leads to several responses (vascular dilatation, ocular hypertension, etc.) which are mediated by prostaglandins (Bethel and Eakins, 1971; Cole and Unger, 1973). In this paper the influence of an inhibitor of prostaglandin synthesis, indomethacin, on lens regeneration in the newt (Notophthalmus viridescens) is investigated in vivo. 


\section{Material and Methods}

Adult newts obtained from Bill Lee Newt Farms, Oak Ridge, Tennessee were anesthetized in ethyl-m-aminobenzoate $(1: 1000)$ and bilaterally lentectomized. They were then injected with indomethacin or carrier solution according to the schedule described below. After the course of injections was completed animals were decapitated and their heads and eyes fixed in Bouin's fluid. Eyes were dissected from the heads and prepared histologically. Regenerates were staged according to Yamada's (1967) description of the progress of regeneration in the Eastern spotted newt, Notophthalmus viridescens. Data were analyzed statistically using the Smirnov nonparametric test (Conover, 1971) after appropriate grouping of results. Since the working hypothesis was that prostaglandins were important in the initial inflammation period or dedifferentiation phase of regeneration long term experiments were not carried out.

Four experiments were performed. Group I-experimental newts received 5 microliters of $100 \%$ ethanol (IP) containing $12 \mathrm{mg} / \mathrm{kg}$ indomethacin (Neufeld et al., 1973) while controls received equivalent volumes of the carrier. Injections were given every other day beginning on the day of lentectomy and continuing until day 17 . Newts were killed 20 days after lens removal. Group $I I$-indomethacin was dissolved in $100 \%$ ethanol and then diluted to $70 \%$ immediately prior to injection. The dose of indomethacin was increased to $120 \mathrm{mg} / \mathrm{kg}$ and the injection volume was 7 microliters. Dilution just prior to injection reduced mortality and avoided precipitation of the drug in lower alcohol concentrations. Animals were injected every other day and were killed on day 17 after lens removal. Group III-Animals were injected with $0.05 \mathrm{ml}$ saline containing a suspension of indomethacin $(1.2$ or $2.4 \mathrm{mg} / \mathrm{kg}$ ). Controls received saline alone. Newts were injected until day 15 after lens removal. Group IV-indomethacin was completely dissolved in phosphate buffer at $\mathrm{pH} 7.9$. Newts were injected as described above with a dose of $12 \mathrm{mg} / \mathrm{kg}$ over a 15 day period. Controls received buffer alone.

\section{Results}

The results of all the experiments are summarized in Table 1. Injection of even a minute amount of ethanol resulted in about $30 \%$ mortality among both control and experimental newts. A Smirnov analysis of the stages of regeneration attained by animals in Group I revealed no significant differences between treated

Table 1. Influence of indomethacin on lens regeneration in vivo

\begin{tabular}{|c|c|c|c|c|c|c|c|c|c|}
\hline \multirow[t]{2}{*}{ Treatment } & \multicolumn{9}{|c|}{ Developmental stage } \\
\hline & 2 & 3 & 4 & 5 & 6 & 7 & 8 & 9 & 10 \\
\hline ETOH Cont ${ }^{a}$ & & & & & & & 8 & 1 & \\
\hline Indometh ${ }^{a}$ & & & & & 1 & 1 & 5 & 3 & 2 \\
\hline ETOH Cont ${ }^{b}$ & 1 & 1 & 6 & 10 & & & & & \\
\hline Indometh ${ }^{\mathrm{b}}$ & & 2 & 10 & 4 & & & & & \\
\hline Saline Cont ${ }^{\mathrm{e}}$ & & & 3 & 14 & 6 & 1 & & & \\
\hline Indometh $(1.2)^{\mathrm{C}}$ & & & 1 & 10 & & & 1 & & \\
\hline Indometh $(2.4)^{\mathrm{c}}$ & & & 4 & 6 & 11 & 3 & & & \\
\hline Buffer Cont ${ }^{d}$ & & & & 5 & 3 & 3 & 1 & & \\
\hline Indometh $(12)^{\mathrm{d}}$ & & 1 & & 3 & 4 & 6 & & 5 & \\
\hline
\end{tabular}

a 20 day experiment with $100 \% \mathrm{ETOH}$ as carrier and $12 \mathrm{mg} / \mathrm{kg}$ dose

b 17 day experiment with $70 \%$ ETOH as carrier and $120 \mathrm{mg} / \mathrm{kg}$ dose

c 15 day experiment with saline as carrier and 1.2 or $2.4 \mathrm{mg} / \mathrm{kg}$ dose

d 15 day experiment with phosphate buffer as carrier and $12 \mathrm{mg} / \mathrm{kg}$ dose 
and control newts. Dilution of the ethanol prior to injection lowered mortality in the second group; however, even the higher dose had no effect on the progress of regeneration in Group II. Injection of indomethacin as a saline suspension (Group III) or completely dissolved in phosphate buffer (Group IV) had no effect on regeneration of the lens by 15 days after lens removal.

\section{Discussion}

There is circumstantial evidence that the process of Wolffian lens regeneration is enhanced by the production of a factor from the neural retina in vivo (Reyer, 1966; Yamada, 1967). It is not known exactly what this factor is, how it is produced or precisely when in the regeneration process it acts. No one knows what the signal is which causes the initiation of regenerative events in the iris after lentectomy. For years the existence of "wound hormones" has been hypothesized but never proven in regeneration (Needham, 1952). The possible correlation between prostaglandins and the so-called wound hormones is obvious. Indeed, there is some evidence that drugs which alter prostaglandin levels and prostaglandins themselves affect limb regeneration ability in anurans (McCartney and Mulcare, 1973). Since prostaglandins play such an important role in the ocular response to trauma (Bethel and Eakins, 1971; Cole and Unger, 1973) it was thought worthwhile to attempt to inhibit prostaglandin synthesis by indomethacin treatment in the newt. Obviously, the results of these experiments show no effect of the drug on lens regeneration in the regimen used. It is possible that intracameral injections might have produced different results. However, since the corneal incision made at lentectomy is large considerable leakage of the drug would have occurred following injection directly into the eye. It is difficult to know if the drug as used in these experiments actually had an effect on prostaglandin levels in the eye or elsewhere in the newt's bodies. The animals are small and measurement of prostaglandin levels in the ocular environment over the course of these experiments would have required an unwarranted number of newts. These experiments do not prove that prostaglandins are not involved as mediators of the iris response to lentectomy which leads to lens regeneration, but suggest that additional experiments using other prostaglandin antagonists or stimulators should be performed to determine if prostaglandins are actually involved in the initiation of lens regeneration in the adult newt.

Thanks are due to Mr. Jerry Zolit and Ms. E.K. Ashcraft for technical assistance during the performance of these experiments and to Mrs. Anita Graham for help in preparing the manuscript. This work was supported partially by a grant from the Horace H. Rackham School of Graduate Studies, U of M, and partially by a grant (HD 08150) from the USPHS.

\section{References}

Bethel, R.A., Eakins, K.E.: The mechanism of the antagonism of experimentally induced ocular hypertension by polyphloretin phosphate. Exp. Eye Res. 13, 83-91 (1971)

Cole, E.F., Unger, W.G.: Prostaglandins as mediators for the responses of the eye to trauma. Exp. Eye Res. 17, 357-368 (1973) 
Conover, W.J.: Practical nonparametric statistics. New York: John Wiley and Sons 1971

Dumont, J.N., Yamada, T.: Dedifferentiation of iris epithelial cells. Develop. Biol. 29, 385-410 (1972)

McCartney, J.C., Mulcare, D.: Anuran forelimb regeneration after prostaglandin treatment. Amer. Zool. 13, 1351 (1973)

Needham, A.E.: Regeneration and wound-healing. United Kingdon: Methuen 1952

Neufeld, A.H., Chavis, R.M., Sears, M.L.: Evidence for prostaglandin synthesis and release caused by degenerating sympathetic nerve terminals in the rabbit eye. In: Prostaglandins and CAMP (eds. R.H. Kahn, W.E.M. Lands), pp. 25-27. New York: Academic Press 1973

Reese, D.H.: In vitro initiation in the newt iris of some early molecular events of lens regeneration. Exp. Eye Res. 17, 435-444 (1973)

Reese, D.H., Puccia, E., Yamada, T.: Activation of ribosomal RNA synthesis in initiation of Wolffian lens regeneration. J. exp. Zool. 170, 259-268 (1969)

Reyer, R.W.: The influence of neural retina and lens on lens regeneration from dorsal iris implants. Develop. Biol. 14, 214-215 (1966)

Yamada, T.: Cellular and subcellular events in Wolffian lens regeneration. Curr. Top. Develop. Biol. 2, 247-283 (1967)

Yamada, T., Roesel, M., Beauchamp, J.J.: Cell cycle parameters in dedifferentiating iris epithelial cells. J. Embryol. exp. Morph. 34, 497-510 (1975)

Note Added in Proof. Since this paper was accepted for publication the effects of prostaglandins on lens regeneration in vivo have also been tested. Lentectomized newts received either $\mathrm{PGE}_{1}$ or $\mathrm{PGF}_{1 \alpha}$ (each 2.5 or 5.0 microgram/animal) every other day for 15 days. Controls received equivalent volumes of water. There was no significant effect of either of these treatments on regeneration in any of the groups of animals in this experiment.

Received June 10, 1976 